\section{Efficacy of intravenous ondansetron to prevent vomiting episodes in acute gastroenteritis: a randomized, double blind, and controlled trial}

\author{
Sanguansak Rerksuppaphol, \\ Lakkana Rerksuppaphol ${ }^{2}$ \\ 'Department of Paediatrics and \\ ${ }^{2}$ Department of Preventive Medicine, \\ Faculty of Medicine, Srinakharinwirot \\ University, Thailand
}

\section{Abstract}

Acute gastroenteritis is one of the most common infectious diseases of childhood. Its symptoms are vomiting, diarrhea, and dehydration. In the emergency ward, intravenous rather than oral rehydration is usually preferred because of the high likelihood of emesis. Treatments to reduce emesis are of value in improving the rehydration procedure. Our study is a double-blind randomized trial and proposes the use of ondansetron as an antiemetic drug to treat children with acute gastroenteritis. Seventy-four in-patients, aged 3 months to 15 years, were enrolled and randomly assigned to an ondansetron or placebo group. Inclusion criteria were the diagnosis of acute gastroenteritis and the absence of other diseases or allergies to drugs. A single bolus $(0.15 \mathrm{mg} / \mathrm{kg})$ of ondansetron was injected intravenously; normal $0.9 \%$ saline solution was used as a placebo. This treatment induced vomiting cessation in the ondansetron group significantly in comparison to the placebo group. The length of the hospital stay and the oral rehydration fluid volume were similar in the two groups and no adverse effects were noticed. Thus, safety, low cost, and overall benefit of ondansetron treatment suggests that this drug can be administered successfully to children with acute gastroenteritis.

\section{Introduction}

Acute gastroenteritis is a common illness in childhood. Frequently caused by viruses, its symptoms include vomiting, diarrhea, abdominal pain, and fever. No therapy is suggested for viral infections, while dehydration caused by diarrhea and emesis should be treated vigorously. ${ }^{1}$ In emergency departments, physicians usually choose intravenous over oral rehydration when vomiting is the most impor- tant symptom, even if oral rehydration is recommended for mild to moderate dehydration. ${ }^{2}$ Thus, reducing emesis is the first goal to assure the preference and the success rate of oral dehydration. ${ }^{3}$ Anti-emetic treatments could have potential benefits but some concerns about the adverse effects, such as extrapyramidal symptoms or lethargy, discourage their use. ${ }^{4}$ Ondansetron is a novel anti-emetic drug currently used to treat nausea and vomiting associated with antineoplastic therapies in children and adults. ${ }^{5}$ Its activity as a serotonin 5-HT3 receptor antagonist prevents extrapyramidal effects. ${ }^{5}$ For this reason, ondansetron has been studied for a possible use in acute gastroenteritis in children. Ondansetron has shown greater effectiveness in reducing vomiting when compared with metoclopramide, a common anti-emetic or placebo, but has an increased incidence of diarrhea ${ }^{6}$ Furthermore, intravenous ondansetron administration in a double-blind trial in the emergency department has significantly reduced emesis, diarrhea, and hospital admission rates, confirming the cost-benefit ratio associated with this pharmaceutical approach. Based on this preliminary evidence, our present study shows the result of a single dose of intravenous ondansetron in the in-patient setting in Thai children.

\section{Materials and Methods}

Our study was a prospective, double-blind, randomized comparison between ondansetron and a placebo to reduce emesis in children affected by acute gastroenteritis. The trial was conducted at the pediatric in-patient ward of the Srinakharinwirot University Hospital from January 2008 to October 2008. The Ethics Committee of the Faculty of Medicine at the Srinakharinwirot University approved the protocol study. Children, from 3 months to 15 years old, who vomited more than three times in the 24 hours prior to admission and had acute gastroenteritis symptoms, were eligible for the study. Parents or legal guardians of children who met eligible criteria were asked to sign a written informed consent form. Treatment with any anti-emetic drug within 24 hours before enrolment or any history of a chronic medical condition such as hepatic disease, cardiovascular disease, chronic respiratory disease, immunodeficiency, tumors, diabetes mellitus, chronic gastrointestinal conditions, behavioral or psychiatric problems, or other neurological conditions were considered as exclusion criteria. Children who had a history of any drug allergy were also excluded. After enrolment, demographic characteristics and clinical data were recorded by nursing staff. Weight to the nearest $100 \mathrm{~g}$ and height to
Correspondence: Sanguansak Rerksuppaphol, Department of Paediatrics, Faculty of Medicine, Srinakharinwirot University, 62 Mo 7, RangsitNakorn Nayok Rd., Nakorn/Nayok, Thailand 26120. E-mail: sanguansak_r@hotmail.com

Key words: emesis, children, acute gastroenter itis, double-blind trial, ondansetron.

Contributions: both authors of this collaborative work defined the research theme. SR designed the methods and experiment, carried out the experiment, analyzed the data, interpreted the results, and wrote the paper. LR co-designed the experiment, and co-worked on associated data collection and their interpretation. Both authors have contributed to, read, and approved the manuscript.

Acknowledgments: the present study was sup ported by grants from the Faculty of Medicine, Srinakharinwirot University, Thailand. We also thank Elisa Sala for editing the manuscript.

Conflict of interest: the authors report no conflict of interest.

Received for publication: 16 April 2010.

Revision received: 31 July 2010.

Accepted for publication: 10 September 2010.

This work is licensed under a Creative Commons Attribution 3.0 License (by-nc 3.0).

○C Copyright S. Rerksuppaphol and L. Rerksuppaphol 2010

Licensee PAGEPress, Italy

Pediatric Reports 2010; 2:e17

doi:10.4081/pr.2010.e17

the nearest millimeter were measured. To classify the hydration status, the World Health Organization criteria were adopted on admission; Table 1 summarizes the scale.

Participants were randomized in two groups by a computerized program using a block of two, and were assigned to the ondansetron group or placebo group. After intravenous blood access for baseline biochemistry and fluid resuscitation, patients received a single bolus of intravenous ondansetron (Zofran, Glaxo Wellcome Inc.) at the dose of $0.15 \mathrm{mg} / \mathrm{kg}$ up to the maximal dose of $8 \mathrm{mg}$ over $2 \mathrm{~min}$. Children who were assigned to the control group were treated intravenously with $0.9 \%$ of normal saline solution, the same amount as the ondansetron treatment, and over 2 min as well. Attending physicians were responsible for the treatment protocol and discharge from the hospital. The primary outcome was the number of vomiting episodes after drug administration. We defined a vomiting episode as a forceful expulsion of stomach contents that was separated from the previous one by 
more than 2 min. Non-productive retching, spilling of oral contents, and drooling were not considered vomiting. The secondary outcomes were the volume of intravenous and oral rehydration fluid, length of hospital stay, and adverse effects. The results were presented descriptively as mean, SD, and percent values. The Pearson chi-square or Fisher exact test were used to compare proportions between the two groups. Continuous variables were compared by using a Student t-test. Comparison of ordinal variables between groups was done by the Mann-Whitney U test. Statistical analysis was performed with the SPSS 11.0 software package. The P-value of $<0.05$ was considered as statistically significant.

\section{Results}

One hundred and eight potentially eligible patients were approached to enroll for the study. Of these, 74 patients accepted the invitation to join and were randomly assigned to two treatment groups: one treated with ondansetron and the other treated with the placebo, as a control. The mean age was $3.2 \mathrm{yr}$ (SD 2.6; range $3 \mathrm{mth}$ to $12 \mathrm{yr}$ ) and thirty-eight patients (51.4\%) were boys. Firstly, we evaluated the clinical presentation in terms of the mean number of vomiting episodes during the $24 \mathrm{hr}$ before admission, mean onset, and last vomiting incident before admission. Data are reported in Table 2.

Fifty-two children $(70.3 \%)$ were graded as having mild dehydration by attending physicians at the time of admission. There were no significant differences in baseline characteristics including demographics, clinical presentations, and hematological and biochemistry parameters between the groups (Table 2). No patient had hypernatremia or hypokalemia. Severe metabolic acidosis (bicarbonate $<15$ $\mathrm{mE} / \mathrm{L}$ ) on admission was reported in five and two patients in the ondansetron and placebo groups, respectively. Outcomes of treatment are presented in Table 3.

After drug administration, 30 (81.1\%) patients in the ondansetron group completely ceased vomiting as compared to 9 (24.3\%) patients of the placebo group $(\mathrm{P}<0.01)$. The mean number of vomiting episodes after drug administration was significantly lower in the ondansetron group than in the placebo group ( 0.5 vs. $2.1, \mathrm{P}<0.01$ ). Median time of complete cessation in the placebo group was $10 \mathrm{hr}$ while emesis ceased immediately in the ondansetron group. No significant differences in length of hospital stay, volume of intravenous fluid, and oral rehydration fluid administration were observed between the groups. We did not observe any adverse effect in either group.
Table 1. Scale of hydration status.

\begin{tabular}{ll} 
Normal or mild dehydration & Symptoms \\
Moderate dehydration & No signs or symptoms \\
& $\begin{array}{l}\text { Thirsty, restless or irritable behavior, decreased skin } \\
\text { elasticity, sunken eyeballs }\end{array}$ \\
\hline Severe dehydration & $\begin{array}{l}\text { Shock or diminished consciousness, lack of urine } \\
\text { output, cool and moist extremities, low blood } \\
\text { pressure, rapid and feeble pulse }\end{array}$ \\
\hline
\end{tabular}

Table 2. Demographic description of ondansetron and placebo groups.

\begin{tabular}{|c|c|c|}
\hline & $\begin{array}{l}\text { Ondansetron } \\
\qquad(\mathrm{N}=37)\end{array}$ & $\begin{array}{l}\text { Placebo } \\
(\mathrm{N}=37)\end{array}$ \\
\hline Age $(y r) ;$ mean \pm SD & $3.4 \pm 2.8$ & $3.0 \pm 2.5$ \\
\hline Median (range) & $2.6(0.3-12.0)$ & $2.3(0.3-10.4)$ \\
\hline \% Boy & $21(56.8)$ & $17(45.6)$ \\
\hline Weight (kg) & $14.9 \pm 6.1$ & $12.8 \pm 4.2$ \\
\hline Height $(\mathrm{cm})$ & $97.4 \pm 16.6$ & $92.7 \pm 20.0$ \\
\hline Number of vomiting in previous $24 \mathrm{hr}$; mean $\pm \mathrm{SD}$ & $6.7 \pm 4.5$ & $7.5 \pm 3.9$ \\
\hline Last vomiting prior to admission; $\mathrm{hr} \pm \mathrm{SD}$ & $3.1 \pm 3.5$ & $2.4 \pm 2.2$ \\
\hline Onset of vomiting prior to admission; $\mathrm{hr} \pm \mathrm{SD}$ & $23.2 \pm 21.6$ & $28.4 \pm 24.6$ \\
\hline Presence of diarrhea; $n$ (\%) & $18(48.6)$ & $27(73.0)$ \\
\hline Number of diarrhea episodes in previous $24 \mathrm{hr}$; median (range) & $4.2 \pm 3.0$ & $6.1 \pm 4.7$ \\
\hline Fever $>38.5^{\circ} \mathrm{C} ; \mathrm{n}(\%)$ & $3(8.1)$ & $7(18.9)$ \\
\hline Previous visit to a physician; $\mathrm{n}(\%)$ & $17(45.9)$ & $20(54.0)$ \\
\hline $\begin{array}{l}\text { Hydration status; } n(\%) \\
\text { Mild or no dehydration } \\
\text { Moderate dehydration }\end{array}$ & $\begin{array}{l}26(70.3) \\
11(29.7)\end{array}$ & $\begin{array}{l}26(70.3) \\
11(29.7)\end{array}$ \\
\hline Sodium (mEq/L) & $134.7 \pm 2.1$ & $135.8 \pm 3.3$ \\
\hline Potassium $(\mathrm{mEq} / \mathrm{L})$ & $4.2 \pm 0.4$ & $4.1 \pm 0.7$ \\
\hline Bicarbonate $(\mathrm{mEq} / \mathrm{L})$ & $18.9 \pm 4.1$ & $18.5 \pm 3.7$ \\
\hline BUN & $15.0 \pm 5.0$ & $13.5 \pm 5.5$ \\
\hline Creatinine & $0.5 \pm 0.2$ & $0.5 \pm 0.2$ \\
\hline Urine specific gravity & $1.018 \pm 0.005$ & $1.017 \pm 0.006$ \\
\hline Hematocrit (\%) & $34.8 \pm 2.5$ & $35.4 \pm 3.3$ \\
\hline Hemoglobin (g/dL) & $11.8 \pm 0.9$ & $12.0 \pm 1.4$ \\
\hline White blood cell count & $9439 \pm 4587$ & $9299 \pm 5620$ \\
\hline
\end{tabular}

Table 3. Outcomes measurements.

\begin{tabular}{|c|c|c|c|}
\hline & $\begin{array}{l}\text { Ondansetron } \\
(\mathrm{N}=37)\end{array}$ & $\begin{array}{r}\text { Placebo } \\
(\mathrm{N}=37)\end{array}$ & $\mathbf{P}$ \\
\hline \multicolumn{4}{|l|}{ Number of vomiting episodes; n (\%) } \\
\hline Mean \pm SD & $0.5 \pm .2$ & $2.1 \pm 1.9$ & $<0.01$ \\
\hline Median (range) & $0(0-5)$ & $2(0-7)$ & $<0.01$ \\
\hline Cessation of vomiting & $30(81.1)$ & $9(24.3)$ & $<0.01$ \\
\hline 1 episode & $3(8.1)$ & $5(13.5)$ & \\
\hline 2 episodes & $1(2.7)$ & $10(27.0)$ & \\
\hline$\geq 3$ episodes & $3(8.1)$ & $13(35.1)$ & \\
\hline \multicolumn{4}{|l|}{ Last vomiting after drug administration; hr } \\
\hline Mean \pm SD & $4.2 \pm 11.3$ & $13.5 \pm 13.6$ & $<0.01$ \\
\hline Median (range) & $0(0-53)$ & $10(0-56)$ & $<0.01$ \\
\hline Intravenous fluid received $(\mathrm{mL} / \mathrm{kg} / \mathrm{hr}) ;$ mean $\pm \mathrm{SD}$ & $4.3 \pm 1.3$ & $4.1 \pm 1.4$ & 0.65 \\
\hline Oral rehydration solution $(\mathrm{mL} / \mathrm{kg} / \mathrm{hr}) ;$ mean $\pm \mathrm{SD}$ & $1.9 \pm 1.7$ & $1.3 \pm 1.0$ & 0.15 \\
\hline Length of hospital stay (hr); mean \pm SD & $53.8 \pm 61.3$ & $60.5 \pm 46.6$ & 0.60 \\
\hline
\end{tabular}




\section{Discussion}

Our study provides evidence that an intravenous dose of ondansetron could be useful in reducing emesis associated to acute gastroenteritis. We have investigated 74 children, aged from 3 months to 15 years, admitted to the pediatric ward with a diagnosis of moderate or severe dehydration, in accordance with the World Health Organization guidelines. Previous studies enrolled children as outpatients $;,{ }^{78}$ however, we chose to enroll children in the in-patient setting in order to minimize the difference in the rehydration procedure and, in general, in overall treatment. Furthermore, we reduced the interference from a single physician by counting the number of vomiting episodes after treatment and complete emesis cessation as primary outcomes. In addition, we analyzed the length of hospital stay, volume of intravenous fluid, and oral fluid administration as secondary outcomes, without observing any significant differences between the ondansetron and placebo groups.

Results reported in our study show agreement with those of previous clinical studies conducted in the emergency department. We decided to use a single intravenous dose because no solution is available for this medication and it may have been difficult to orally administer a tablet to young children. Intravenous ondansetron treatment $(0.15$ $\mathrm{mg} / \mathrm{kg}$ ) favors vomiting cessation in $70 \%$ of patients in comparison to $51 \%$ of the placebo group and, consequently, reduces the need for admission to the pediatric ward. ${ }^{7}$ This positive effect may compensate for the cost of the drug, which is not cheap. Furthermore, oral ondansetron treatment shows that children vomit less often and tolerate an oral rehydration procedure better. ${ }^{8}$ In addition, a higher mean incidence of diarrhea in an oral ondansetron group has been described, while intravenous treatment seems to decrease episodes of diarrhea. ${ }^{7,8}$ There is no evidence of other adverse effects in cardiovascular or respiratory systems. ${ }^{8}$ A possible limitation of these studies is the inclusion criteria; indeed, considering a set number of vomiting episodes within the previous 24 hours could have included patients with milder cases of acute gastroenteritis, inducing a too optimistic evaluation of the ondansetron treatment. However, current evidence demonstrates clinical benefits in the use of ondansetron as an anti-emetic in children with acute gastroenteritis.

\section{References}

1. Burkhart DM. Management of acute gas- troenteritis in children. Am Fam Physician 1999;60:2555-63, 2565-6.

2. Ozuah P0, Avner JR, Stein RE. Oral rehydration, emergency physicians, and practice parameters: a national survey. Pediatrics 2002;109:259-61.

3. Reis EC, Goepp JG, Katz S, Santosham M. Barriers to use of oral rehydration therapy. Pediatrics 1994;93:708-11.

4. Kwon KT, Rudkin SE, Langdorf MI. Antiemetic use in pediatric gastroenteritis: a national survey of emergency physicians, pediatricians, and pediatric emergency physicians. Clin Pediatr (Phila) 2002;41:641-52.

5. Culy CR, Bhana N, Plosker GL. Ondansetron: a review of its use as an antiemetic in children. Paediatr Drugs 2001;3:44179.

6. Cubeddu LX, Trujillo LM, Talmaciu I, Gonzalez V, Guariguata J, Seijas J, et al. Antiemetic activity of ondansetron in acute gastroenteritis. Aliment Pharmacol Ther 1997;11:185-91.

7. Reeves JJ, Shannon MW, Fleisher GR. Ondansetron decreases vomiting associated with acute gastroenteritis: a randomized, controlled trial. Pediatrics 2002;109:e 62.

8. Freedman SB, Adler M, Seshadri R, Powell EC. Oral ondansetron for gastroenteritis in a pediatric emergency department. $\mathrm{N}$ Engl J Med 2006;354:1698-705. 